\title{
TEORIA DA VALORAÇÃO COMO ARCABOUÇO TEÓRICO PARA ANÁLISE DO ETHOS PRÓ- FEMINISTA DA PROTAGONISTA DA OBRA VERSAILLES NO BARA
}

Rafael Schuabb Poll da Fonseca ${ }^{1}$

Resumo: A história em quadrinhos Versailles no Bara ("Rosa de Versalhes", em tradução livre) mangá voltado para o público jovem feminino - foi lançado em 1972 no Japão, na revista Margaret. Naqueles anos a segunda onda do feminismo difundia-se cada vez mais na patriarcal e tradicionalmente hierarquizada sociedade japonesa. A protagonista do mangá Versailles no Bara, Oscar François de Jarjayes, uma militar de alta patente, apresenta posturas que parecem refletir alguns dos ideais feministas. Pretende-se neste artigo, então, a partir da perspectiva da Teoria da Valoração, examinar os elementos no discurso de Oscar que justifiquem e reflitam o ethos de uma mulher forte e não submissa que, dentro da trama, alcança uma alta posição social e militar em uma sociedade machista e que, para além do mangá, se torna um ícone do feminismo naquela época.

Palavras-chave: teoria da valoração; ethos; feminismo; mangá; Japão.

\begin{abstract}
The comic Versailles no Bara ("Rose of Versailles" in free translation) - manga targeted toward young women - was released in Japan in 1972, inside the Margaret magazine. In those years the second wave of feminism was spreading increasingly in traditionally hierarchical and patriarchal Japanese society. The protagonist of the manga Versailles no Bara, Oscar François de Jarjayes, a high-ranking military, shows attitudes that seem to reflect some of the feminist ideals. It is intended in this article, then, by the perspective of the Appraisal Theory, examine the elements in the Oscar speech to justify and reflect the ethos of a strong and not submissive woman who, in the plot, reaches a high social status and military in a sexist society and, out of the series, becomes an icon of feminism in those days.
\end{abstract}

Keywords: appraisal theory; ethos; feminism; manga; Japan.

1. Formado em Letras Português/Japonês e mestrando de Linguística na UERJ. 


\section{Introdução}

O presente trabalho tem como objeto de análise o mangá - termo que se refere às histórias em quadrinhos de origem japonesa - Versailles no Bara ("Rosa de Versalhes", em tradução livre), que foi lançado em 1972 no Japão.

Ambientado na França da segunda metade do século XVIII, com especial ênfase às problemáticas sociais que em 1789 dariam origem à Revolução Francesa, o mangá Versailles no Bara é baseado em fatos reais, reconstituindo diversos acontecimentos marcantes daquele período histórico. A protagonista da história é a jovem Oscar, militar de alta patente, inicialmente responsável pela então princesa Maria Antonieta.

Após apresentar resumidamente a história do manga e do shôjo - mangá voltado para o público jovem feminino - e a obra Versailles no Bara, pretendo examinar os elementos no discurso de Oscar que justifiquem e reflitam uma mulher forte e não submissa que, dentro da trama, alcança uma alta posição social e militar em uma sociedade machista e que, para além do mangá, é idolatrada por seus leitores a ponto de a elegerem como protagonista da obra e de que sua morte no final da história cause comoção entre as jovens japonesas dos anos 1970, tornando-se a partir daquele momento um símbolo feminista para a tradicionalmente patriarcal sociedade japonesa.

\section{Corpus de Análise e Metodologia}

O corpus de análise deste trabalho se constitui de alguns recortes do mangá Versailles no Bara, traduzidos por mim mesmo de modo a facilitar o acesso à pesquisa. Para a seleção deles o único filtro que utilizei foi o fato de que deveriam conter prioritariamente falas da personagem Oscar, que é sobre a qual meu interesse teórico recai. Excluindo-se esse fator, minha preocupação foi a de selecionar recortes que se distribuíssem ao longo da trama, de modo a poder contemplar diversos momentos da narrativa.

O desenrolar da trama de Versailles no Bara, de acordo com as decisões e posicionamentos de Oscar perante as injustiças sociais que ocorrem ao seu redor, torna explícitos os valores feministas presentes na heroína da obra. Porém, uma vez que o meu objeto de trabalho é o material linguístico e não a trama em si, decidi tomar como corpus de análise recortes desse mangá em que eu pudesse identificar padrões no discurso da protagonista da obra que garantissem à ela o status de símbolo feminista que recebeu nos anos 1970 por seus leitores. Em outras palavras: buscar as marcas discursivas que justificam a formação do ethos de uma mulher situada na França do século XVIII que se posiciona de acordo com os ideais feministas do Japão dos anos 1970. 
Através do emprego do arcabouço teórico da Teoria da Valoração de Martin e White, pretendo pontuar alguns elementos discursivos da personagem principal da acima citada história em quadrinhos. Aplicando os conceitos dos subsistemas de engajamento, gradação e atitude, viso a encontrar padrões no discurso da protagonista Oscar que reflitam e justifiquem a formação da imagem (ou ethos, como explicarei adiante) de uma personagem feminina que conquistou o posto de personagem principal, que originalmente se destinava a Maria Antonieta, e que foi alçada por toda uma geração ao posto de símbolo feminista na década de 1970, na qual o movimento feminista ganhou fôlego no Japão.

Acredito que a busca por padrões através da Teoria da Valoração possa abrir novas perspectivas para minha pesquisa de mestrado - que trata do ethos da protagonista Oscar, sendo fundamentada na Análise do Discurso francesa (AD) -, afinal, ao olhar o mesmo material sob um novo ponto de vista é possível enxergar detalhes antes imperceptíveis. Além disso, uma vez que se encontrem de fato padrões no discurso de Oscar que reforcem sua imagem (ethos) de mulher em harmonia com os ideais feministas, poderei buscar compreender como a AD francesa lida com essa perspectiva dentro dos próprios arcabouços teóricos dos quais se utiliza.

\section{Fundamentação Teórica}

Uma vez que a proposta para a realização do presente artigo era a de escolher um conceito utilizado pela Análise Crítica do Discurso (ACD) e empregá-lo de modo que pudesse ser útil à minha pesquisa de mestrado, escolhi a Teoria da Valoração, dos teóricos Martin e White, por acreditar que possa ser uma ferramenta útil para a análise do discurso da personagem Oscar, objetivando compreender a formação do ethos da protagonista.

A Teoria da Valoração é uma extensão das teorias linguísticas de Halliday e é o resultado de quase quinze anos de estudo de um grupo de pesquisadores da Universidade de Sidnei, na Austrália, liderados pelo Professor James Martin (http:// www.grammatics.com/appraisal/index.html). Segundo escreve Peter White em seu site, a Teoria da Valoração se ocupa dos recursos linguísticos através dos quais o enunciador se expressa, negocia e naturaliza posições ideológicas e interpessoais.

Esse arcabouço teórico se divide em três subsistemas: engajamento, gradação e atitude.

O engajamento se refere aos elementos textuais que demonstram o comprometimento do enunciador com o que defende em seu discurso e sobre como ele dialoga ou não essa posição com seus interlocutores. Considera-se nesse ponto, por exemplo, recursos textuais através dos quais é possível verificar se o autor busca ou não outras fontes para endossar aquilo que fala; se ele busca atribuir afirmações a 
outras autorias, a fim de tirar de si a responsabilidade total pelo texto, ou se assume total responsabilidade e autoria pelo que diz; se ele dá margem a um diálogo ou não, através de elementos modalizadores como tempos verbais, de palavras e expressões que indicam grau de certeza e de recursos como afirmações categóricas, que quando utilizadas colocam-se como verdades absolutas - "isto é assim"

O subsistema da gradação se ocupa da tonalidade conferida ao discurso através da escolha lexical. Por exemplo, "horroroso" é um léxico com um tom mais alto do que "feio", que por sua vez possui um tom mais elevado do que "não bonito"

A atitude se divide em três linhas de análise: afeto, julgamento e apreciação. $\mathrm{O}$ afeto abrange as palavras empregadas para marcar o posicionamento emocional do enunciador em relação a"s" pessoas, objetos, situações etc. O julgamento se refere aos léxicos que indicam uma avaliação normativa das outras pessoas, geralmente de cunho comportamental. A apreciação se destina a uma avaliação mais voltada para a estética e geralmente empregada em relação a elementos concretos ou abstratos.

Outro conceito que abordarei neste artigo, ainda que de modo superficial, já que o foco neste momento é outro, é o de ethos, segundo a definição de Maingueneau, teórico da Análise do Discurso francesa.

Segundo o autor, ethos é a imagem de alguém gerada através de sua enunciação: elementos linguísticos e não linguísticos, em especial os gestuais. Muitas vezes esses elementos se apresentam sem a intenção do enunciador de utilizá-los, porém, mais importante do que compreender a intencionalidade ou não da aparição deles, a AD se preocupa em relacioná-los ao efeito que geram na imagem do enunciador, ou seja, no ethos que geram.

O ethos nada tem a ver com elogios ou críticas feitos a si mesmo durante um discurso, como "eu sou honesto" ou "eu sou corrupto", mas sim com o que o discurso apresenta por si próprio sobre seu enunciador: o ethos se mostra, ele não é dito (MAINGUENEAU, p71). Retomando Ducrot, Maingueneau concorda que

Não se trata de afirmações autoelogiosas que o orador pode fazer sobre sua própria pessoa no conteúdo de seu discurso, afirmações que, ao contrário, podem chocar o ouvinte, mas da aparência que lhe confere a fluência, a entonação, calorosa ou severa, a escolha das palavras, dos argumentos... (DUCROT apud MAINGUENEAU, 2011, p71)

Maingueneau admite a existência de dois tipos de ethos: o discursivo, que se forma durante o ato da enunciação, e o pré-discursivo, que é a imagem do enunciador formada antes do ato da enunciação. Porém, o teórico foca suas atenções ao ethos discursivo. 


\section{Breve Histórico do Mangá}

A arte japonesa, assim como sua cultura, caracterizou-se por se desenvolver de forma independente dos outros países, já que o Japão por muito tempo se manteve fechado para o restante do mundo. Os contatos ocasionais, porém, nunca foram desperdiçados, afinal, os japoneses sempre souberam reconhecer o que havia de bom na cultura alheia e aplicá-la de modo particular e otimizado em sua própria cultura.

Pode-se dizer que uma maior troca de influências entre o Japão e outras nações só começou a ocorrer a partir de 1853, quando navios norte-americanos forçaram o Japão a se abrir para o comércio internacional. Desde então, a influência ocidental floresceu em todos os aspectos da cultura nipônica, como, por exemplo, nas próprias histórias em quadrinhos.

Não há consenso sobre onde e quando apareceram os primeiros quadrinhos no mundo, já que eles nem sempre tiveram uma forma definida como hoje em dia. Porém, a primeira história em quadrinhos tal como conhecemos hoje em dia só surgiu nos em 1894, nos Estados Unidos, com a publicação das tiras Yellow Kid na revista Truth, que criou e definiu os primórdios da linguagem de quadrinhos (NETO, p15).

No Japão, por outro lado, as xilogravuras (gravuras em madeira) são vistas como precursoras dos mangás (LUYTEN, p91-100). O próprio termo "mangá" tornou-se mais conhecido com a publicação da coleção de ilustrações em xilogravura Hokusai Manga, de Katsuhika Hokusai, mais famoso pela estampa $A$ Grande Onda de Kanagawa.

A definição de mangá tal qual é usada atualmente só surgiria através de Rakuten Kitazawa, um dos primeiros quadrinistas japoneses, no início do século $\mathrm{XX}$. Naquela época, os mangás eram publicados em formato de tiras em jornais ou revistas de humor, seguindo um modelo em ascensão na Europa e nos Estados Unidos, e alcançaram certo sucesso no Japão.

Entretanto, as frequentes guerras travadas pelos japoneses contra outros países e os prejuízos decorrentes delas praticamente extinguiram a produção local de histórias em quadrinhos. Com os desastres oriundos de conflitos bélicos, como a Guerra Sino-Japonesa e as duas Guerras Mundiais, o país encontrava-se em ruínas tanto no aspecto material quanto psicológico ao final do ano de 1945. Os japoneses saíram derrotados da Segunda Guerra Mundial, tendo inclusive sofrido dois ataques devastadores de bombas atômicas em seu território. Os fortes problemas econômicos e sociais, distribuídos entre um povo conhecido pelo seu forte orgulho, acabaram gerando comportamentos e hábitos até hoje refletidos na cultura local, como pode ser observado nos mangás. 
Um deles é o fazer muito com pouco, que se refletiu nos mangás. Após a Guerra, a produção de quadrinhos voltou timidamente, com obras publicadas em papel de baixa qualidade. Sendo uma opção barata de entretenimento, era uma das poucas formas de escape encontradas pela população local, que encontrava naquelas histórias meios através dos quais podia se distanciar mentalmente dos problemas pelos quais o Japão estava atravessando e se divertir um pouco, o que acabou favorecendo a indústria nipônica de quadrinhos.

A linguagem e o charme dos mangás formariam um estilo particular a partir do final da década de 40, quando Osamu Tezuka, natural de Osaka, começou a chamar a atenção dos japoneses com a obra Shin Takarajima ("A Nova Ilha do Tesouro", em português). Buscando inspirações nas animações de Walt Disney e de Max Fleischer (de Betty Boop e Popeye), às quais teve acesso através de seu pai durante a infância, o jovem Tezuka, de apenas 19 anos, incorporou a linguagem do cinema no papel, utilizando ângulos ousados e temas mais profundos do que o simples humor barato.

A partir desse momento, o mercado de quadrinhos do Japão cresceu vigorosamente sem qualquer influência ou presença no mercado externo. Grandes editoras americanas de quadrinhos como a Marvel Comics (de X-Men, Vingadores e Homem-Aranha, entre outros) até tentaram introduzir algumas de suas séries de sucesso no Japão, mas foram esmagadas pela avalanche de títulos locais, de maior apelo entre os japoneses.

Apesar do sucesso de alguns desenhos animados japoneses (os chamados animês) no Ocidente, ainda era praticamente nula a publicação de mangás nos continentes americano, europeu e até mesmo em outros países da Ásia. Isso mudou com o sucesso de Akira, filme de animação de 1988, baseado em mangá homônimo. Retratando uma Tóquio futurista e pós-apocalíptica, o longa-metragem chamou a atenção dos americanos e europeus para a estética e conteúdo dos quadrinhos e desenhos animados japoneses.

Isso foi ainda mais acentuado com o advento da internet, que possibilitou uma melhor divulgação dos mangás e animês a uma legião de fãs muito mais abrangente do que os pequenos grupos que existiam até então. A digitalização e o compartilhamento de obras através da internet, geralmente traduzidas/ legendadas, mesmo que de forma polemicamente ilegal, ajudou a difundir essa nova arte nos mercados estrangeiros. A diversidade de gêneros também atraiu pessoas que não liam quadrinhos por não se identificarem com as histórias de super-heróis americanos. Isso incluiu o público feminino, que foi encontrar nos mangás histórias produzidas especialmente para elas.

\section{O Gênero Shôjo}

As histórias em quadrinhos japonesas são direcionadas em função da idade e do sexo de seu público alvo, atendendo aos mais diversos tipos de consumidores: 
desde crianças em fase de alfabetização, passando por adolescentes e seus conflitos característicos, até homens de negócios e donas de casa. Porém, em nenhum outro país se dá tanta atenção às histórias voltadas para o público feminino como no Japão. O shôjo (mangá voltado para meninas) possui peculiaridades gráficas e narrativas, o que permite que seja designado como, além de um tipo específico de mangás voltado para garotas, um estilo diferenciado da arte dos quadrinhos japoneses.

Nos anos 50, os primeiros mangás para meninas foram feitos por homens, como Anmitsu Hime (de Shousuke Kurakane) e Ribbon no Kishi (de Osamu Tezuka), obra responsável por dar um grande impulso aos shôjo. Ambas as obras são protagonizadas por princesas que, por motivos próprios, adotam características masculinas. No caso de Ribbon no Kishi (que poderia ser traduzido como "Guerreiro de Fitas", mas cuja versão em português é "A Princesa e o Cavaleiro"), a princesa precisa ser criada como menino para que possa ter direito ao trono, reservado apenas para homens.

Nos anos 60 ocorreu um grande aumento de autoras de mangás. Uma vez que essas mulheres conheciam melhor o universo feminino do que os autores homens, estes precisaram elaborar melhor suas obras para poderem sobreviver dentro do competitivo mercado de quadrinhos para o público feminino. Dessa forma, a "invasão" das autoras no universo dos shôjo acabou elevando o nível do gênero. Mesmo assim, o shôjo continuou sendo visto como inferior ao shônen, mangá direcionado a garotos.

No início dos anos 70, o mercado de quadrinhos do Japão estava em pleno crescimento graças a grandes autores, como Osamu Tezuka, que firmaram a indústria de mangás no período de pós-guerra. Por causa do movimento feminista, observou-se a retomada de personagens femininas com características masculinas nos shôjo, como é o caso do grande expoente desse período: Versailles no Bara.

O shôjo passou a ter o mesmo respeito e admiração que o shônen justamente por causa de Versailles no Bara, que começou a ser publicado pela jovem autora Riyoko Ikeda na revista Margaret, no ano de 1972.

A trama apresenta uma combinação de elementos que foram considerados pouco adequados ao público-alvo da Margaret, revista que era voltada para meninas de 8 a 14 anos e na qual o mangá foi publicado em capítulos geralmente semanais, como, por exemplos, androginia, relação extraconjugal, prostituição, homossexualidade, suicídio, tentativa de estupro etc.

\section{Versailles no Bara}

O mangá Versailles no Bara tem como cenário a França da segunda metade do século XVIII e para criá-lo a autora Riyoko Ikeda se baseou em uma famosa biografia de Maria Antonieta, escrita pelo austríaco Stefan Zweig. Aos personagens 
históricos reais foram acrescentados alguns fictícios, como é o caso da própria protagonista, a militar Oscar François de Jarjayes.

O enredo, inicialmente mais voltado à vida de Antonieta, logo se concentra na história de Oscar, em suas aventuras e amadurecimento, o que a levará a criticar até mesmo a nobreza francesa, grupo social do qual ela é integrante. Embora seja uma nobre, a heroína percebe a situação miserável em que se encontra a grande maioria do povo francês e acompanha, bastante atenta, os primeiros movimentos daquilo que virá a se tornar a Revolução Francesa.

Oscar-François de Jarjayes é filha de um general nobre ligado à família real. Determinado a manter a tradição militar e a posição social dos Jarjeyes, o pai de Oscar lhe batiza com esse nome masculino e faz com que ela seja educada como se fosse um garoto. Oscar é treinada em esgrima e montaria desde cedo e aos quatorze anos é designada como protetora de Maria Antonieta, que nesse momento, recém chegada à França, ainda é princesa no reino francês. A proximidade entre Oscar e Antonieta acaba por gerar uma relação de grande respeito entre ambas, em meio às tramas que se desenvolvem na vida de aparência e excessos da realeza e da nobreza.

\section{A Segunda Onda do Feminismo}

O Feminismo se consolidou como um discurso de caráter intelectual, filosófico e político que busca romper os padrões tradicionais, acabando assim com a opressão sofrida ao longo da história da humanidade pelas mulheres (http://www. infoescola.com/historia/segunda-onda-feminista). Esse discurso, enquanto movimento social, pode ser dividido em três ondas (ou fases), marcadas por características ideológicas específicas.

Cronologicamente, a Segunda Onda Feminista (difundida principalmente entre os anos 1960 e 1980, período em que o mangá é escrito) pode ser vista como continuidade da Primeira Onda, porém, há singularidades que permitem uma divisão entre os dois períodos. Enquanto na Primeira Onda as mulheres requisitavam direitos políticos, na Segunda, buscavam o fim da discriminação por gênero e defendiam a igualdade entre homens e mulheres.

Dadas as conquistas alcançadas pela Primeira Onda, em 1960 as mulheres desfrutavam de maior espaço nos espaços sociais. $O$ foco das feministas passou a ser, então, o fim do preconceito contra as mulheres e da visão machista do gênero feminino como sexo frágil e prioritariamente estético. Para derrubar essa visão, o Feminismo desse período passou a pregar a igualdade entre os gêneros, ou seja, a afirmar que homens e mulheres eram iguais (o que seria, anos depois, considerado impróprio pelo "Feminismo da Diferença", corrente da Terceira Onda Feminista) e que, portanto, deveriam receber o mesmo tratamento dentro da sociedade. 
Desse modo, a Segunda Onda Feminista passou a criticar a ideia de que as mulheres teriam satisfação em apenas cuidar dos filhos e do lar (http://www. infoescola.com/historia/segunda-onda-feminista). Nesse contexto, a frase "Liberação das mulheres" surgiu nos Estados Unidos e se tornou um dos motes desse período do Feminismo, com as mulheres buscando seu espaço no mercado de trabalho e, assim, a independência financeira.

Esse cenário em que a Segunda Onda Feminista se choca contra a tradicional sociedade japonesa é o contexto social em que Versailles no Bara é publicado, a partir de 1972. Considerando que "a arte é um registro sensível no tempo, que diz como os homens representavam a si mesmos e o mundo" (CATAVENTO apud VALERIA), será possível encontrar nesse mangá voltado ao público infantil fragmentos desse período do Feminismo.

\section{Oscar Encarna os Valores Estéticos do Feminismo}

Nos anos de 1970, A androginia, comum no Japão, estava em voga mais do que nunca no mundo inteiro: aquela foi a época do glam rock, de David Bowie. Pode-se considerar também que a não distinção física entre homens e mulheres serviria como uma ferramenta feminista com a finalidade de aproximar as mulheres aos homens, já que a busca era pela igualdade entre os sexos.

Oscar é dona de uma beleza andrógina. Seu porte masculino é reforçado pelo uso de uniformes militares - ela normalmente não utiliza trajes femininos. Por isso, muitos membros da corte francesa acreditam que ela seja, na verdade, um homem. As damas da nobreza, aliás, são fascinadas por sua elegância, caráter e beleza.

Seu visual masculinizado é reforçado pela espada sempre a postos e por seu cavalo branco, que faz com que sua imagem lembre muitas vezes a de um príncipe dos contos de fadas.

Outro elemento visual de Oscar que liberta a imagem da personagem das rédeas curtas impostas ao gestual das mulheres japonesas dos anos 1970 é o modo como ela ri. No Japão, as mulheres tradicionalmente colocam uma das mãos à frente da boca quando riem. Há o pensamento de que mulheres que riem sem tapar a boca são mal-educadas, ao passo que a mesma recomendação não se aplica aos homens. Oscar, por outro lado, ri e gargalha sem esse tipo de preocupação, ao contrário das outras mulheres da trama, que embora ambientada na França, carregam esse traço típico da sociedade japonesa.

Como descrito acima, o elemento textual imagético ligado à figura de Oscar permite uma análise pró-feminismo bastante abundante e, portanto, será um dos elementos de pesquisa de minha dissertação de mestrado. Embora no presente trabalho eu não vá abordar esse elemento, uma vez que minha opção pelo emprego da Teoria da Valoração se destina à análise de elementos textuais verbais, 
o apresentei muito brevemente aqui por julgá-lo interessante para a compreensão da ideologia feminista presente na obra Versailles no Bara.

\section{Oscar Encarna os Valores Éticos do Feminismo}

Apesar de Versailles no Bara ser ambientado na Europa e de Oscar ser francesa, ela tem uma atitude profundamente japonesa (o que é totalmente justificável pelo fato de ter sido criada por uma autora japonesa). A protagonista, que é uma espadachim talentosa, carrega os valores do bushidô, o rígido código de honra dos antigos samurais nipônicos.

Oscar representa fortemente os ideais feministas que marcaram os anos 1970 no Japão e comuns à Segunda Onda do Feminismo, ao ser uma mulher que desempenha um papel militar socialmente atribuído a homens, propondo assim uma aparente igualdade entre os gêneros, tal qual defendia o Feminismo naquele momento.

Naqueles anos, o movimento feminista estava em seu auge no Japão e um número crescente de moças tentava romper os laços conservadores que as atavam à vida doméstica, buscando a independência financeira e a realização pessoal, inclusive no que diz respeito ao ideal romântico e à negação dos casamentos arranjados (miai), muito comuns até aquela época.

A seguir, apresento brevemente os três principais relacionamentos de Oscar com outros homens da trama, destacando os elementos interessantes ao posicionamento da personagem enquanto mulher que não se submete às expectativas sociais.

\subsection{Geròdere - Oscar rejeita o miai}

Oscar rejeita um pretendente (Geròdere) arranjado por seu pai. Ela recusa o pedido de casamento, derrota o rapaz em um duelo e se torna sua superior no exército. Inicialmente ofendido, Geròdere logo se torna mais um dos admiradores da brava protagonista.

\subsection{Fersen - Oscar coloca sua profissão acima dos sentimentos}

Oscar acaba se apaixonando por Fersen, um conde sueco. Porém, a protagonista abre mão do homem que ama quando percebe que a pessoa que ela, por seu cargo militar, tem obrigação de proteger, Maria Antonieta, também está apaixonada por Fersen. Dessa forma, Oscar coloca seu dever acima de seus sentimentos, sem negar, por outro lado, que isso lhe seja doloroso. 


\subsection{André - Oscar se envolve com um homem hierarquicamente inferior}

Desde a infância, Oscar sempre pôde contar com seu criado e companheiro de esgrima Andre, neto da governanta da casa da família Jarjayes. Porém, o rapaz é apaixonado pela protagonista. Já quase no fim da história, Oscar percebe que também se apaixonou por Andre e decide ficar com ele, apesar de seu pai ser contra.

\section{Análise}

Apresento em seguida os trechos selecionados do mangá Versailles no Bara nos quais há falas da personagem Oscar (para fins de identificação, ela é a mulher de cabelo longo branco - na verdade, ela seria loira caso o mangá colorido). Eles foram escolhidos por exemplificarem de forma consistente os padrões que encontrei ao longo da leitura mediada pelos aparatos da Teoria da Valoração. Após cada trecho, apresento as considerações pertinentes e, na conclusão, exponho os padrões encontrados e como eles refletem na construção do ethos da protagonista da obra.

\subsection{Primeiro trecho}

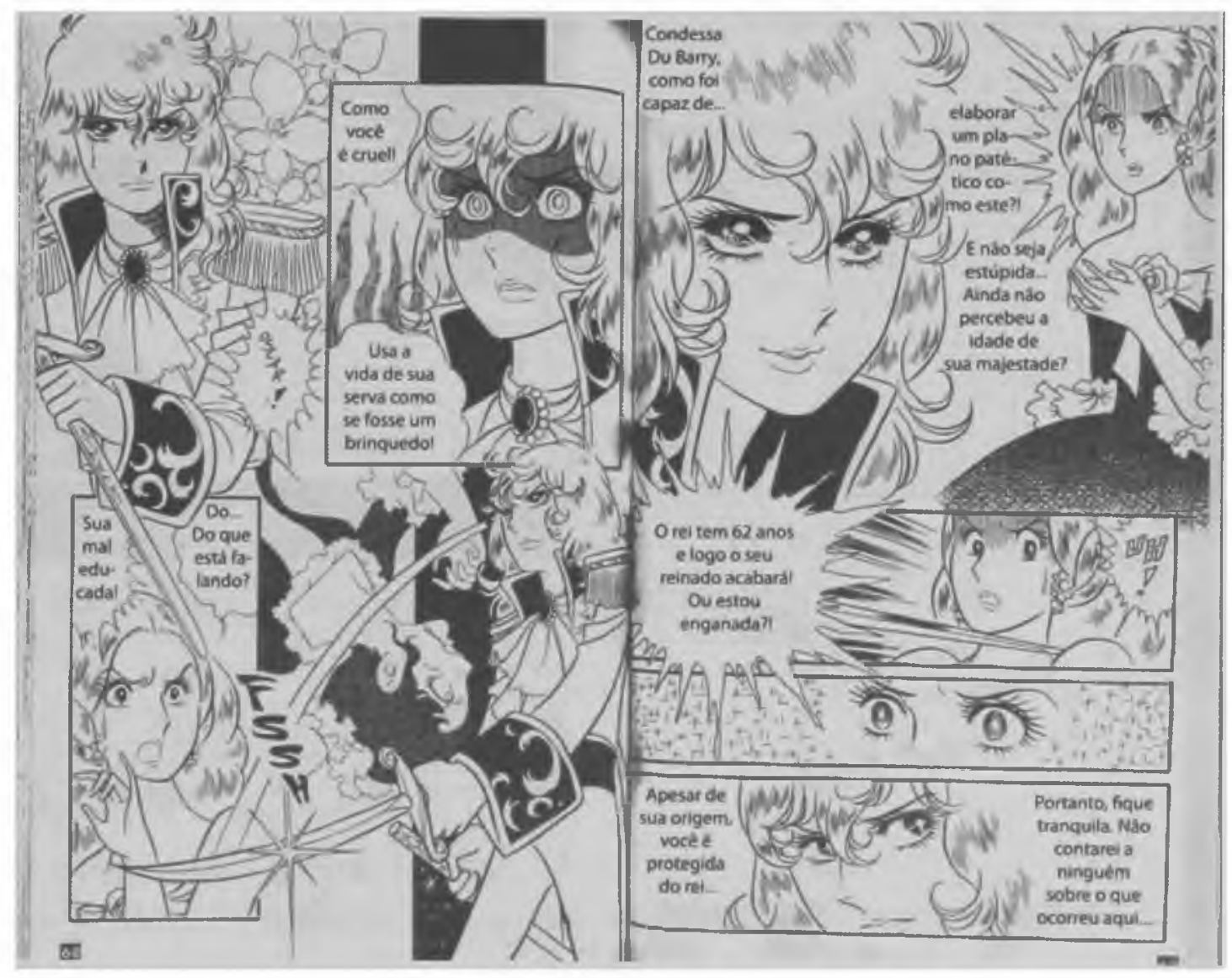




\subsubsection{Engajamento}

Intravocalização: verbos em primeira pessoa para manifestar a autoria de seu discurso. Em frases como "Ou estou enganada?!", assume a responsabilidade da fala.

Modalização: tempos verbais que indicam certeza, como o presente e o futuro do presente do indicativo. Exemplos: "usa a vida", "seu reinado acabará" e "não contarei"

\subsubsection{Gradação}

Léxicos de tom alto: "cruel", "patético", "estúpida". Na frase "Como você é cruel", o léxico "como" funciona como um advérbio de intensidade, com o mesmo sentido de "muito", elevando o tom da frase.

Exclamações: leio as exclamações abundantes no trecho acima como um elemento que eleva ainda mais o discurso de Oscar.

\subsubsection{Atitude}

Predomínio de julgamento: sua atenção é direcionada para o exterior: "cruel", "patético", "apesar de sua origem" 


\subsection{Segundo trecho}

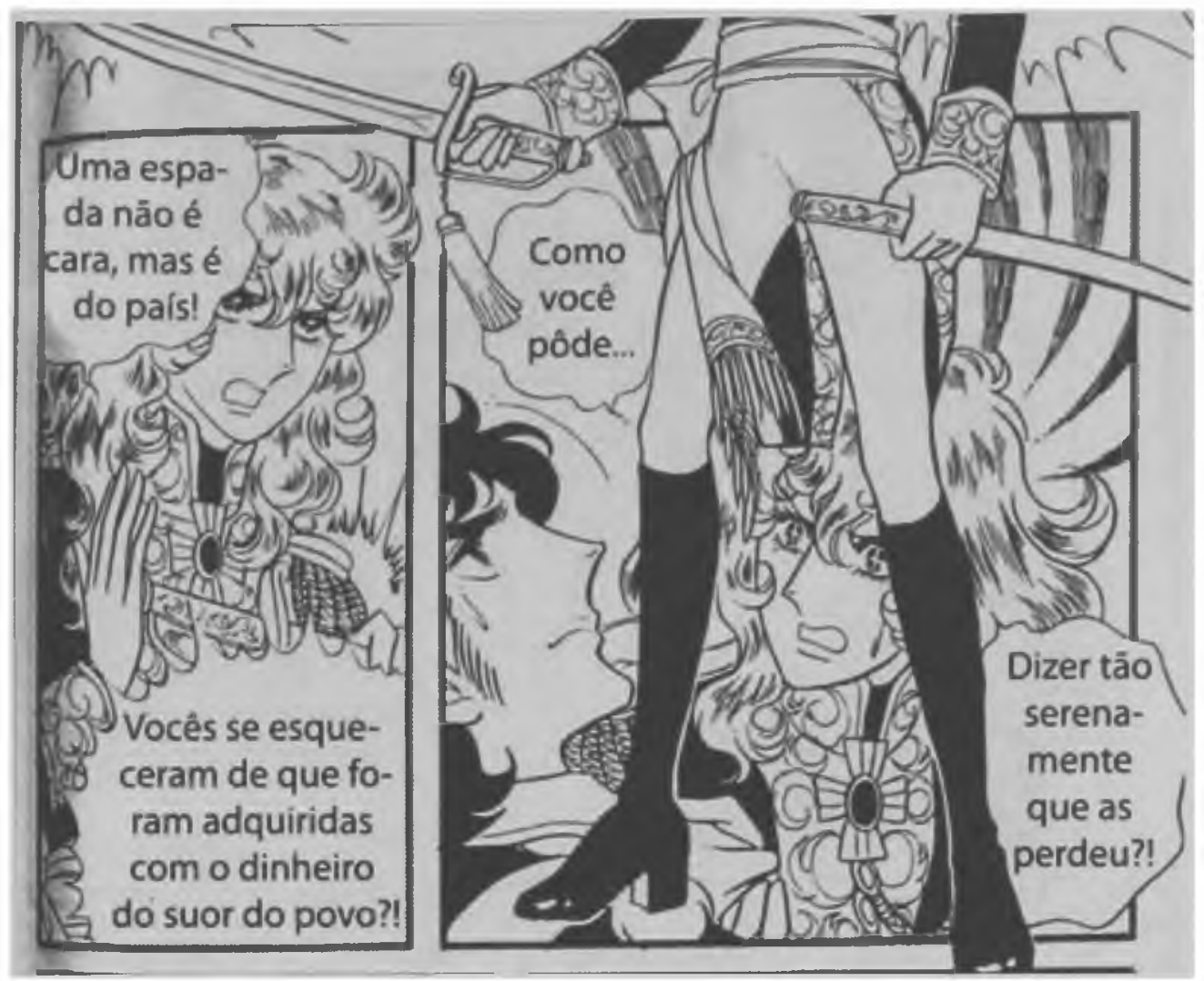

\subsubsection{Engajamento}

Endosso neutro: na frase "Vocês se esqueceram de que foram adquiridas com o dinheiro do suor do povo?!", há uma atribuição implícita a um consenso compartilhado entre a enunciadora e os coenunciadores.

\subsubsection{Gradação}

Léxicos de tom alto: na frase "Dizer tão serenamente que as perdeu?!", além da palavra "tão", o léxico "serenamente", que normalmente tem um papel atenuador, funciona como um acentuador de tom ao ser usado aqui com um tom crítico.

Exclamações: novamente as exclamações acentuam o tom do discurso de Oscar.

\subsubsection{Atitude}

Predomínio de julgamento: em "Como você pôde dizer tão serenamente que as perdeu?!", embora seja um questionamento, Oscar coloca um forte tom crítico em sua fala. 


\subsection{Terceiro trecho}

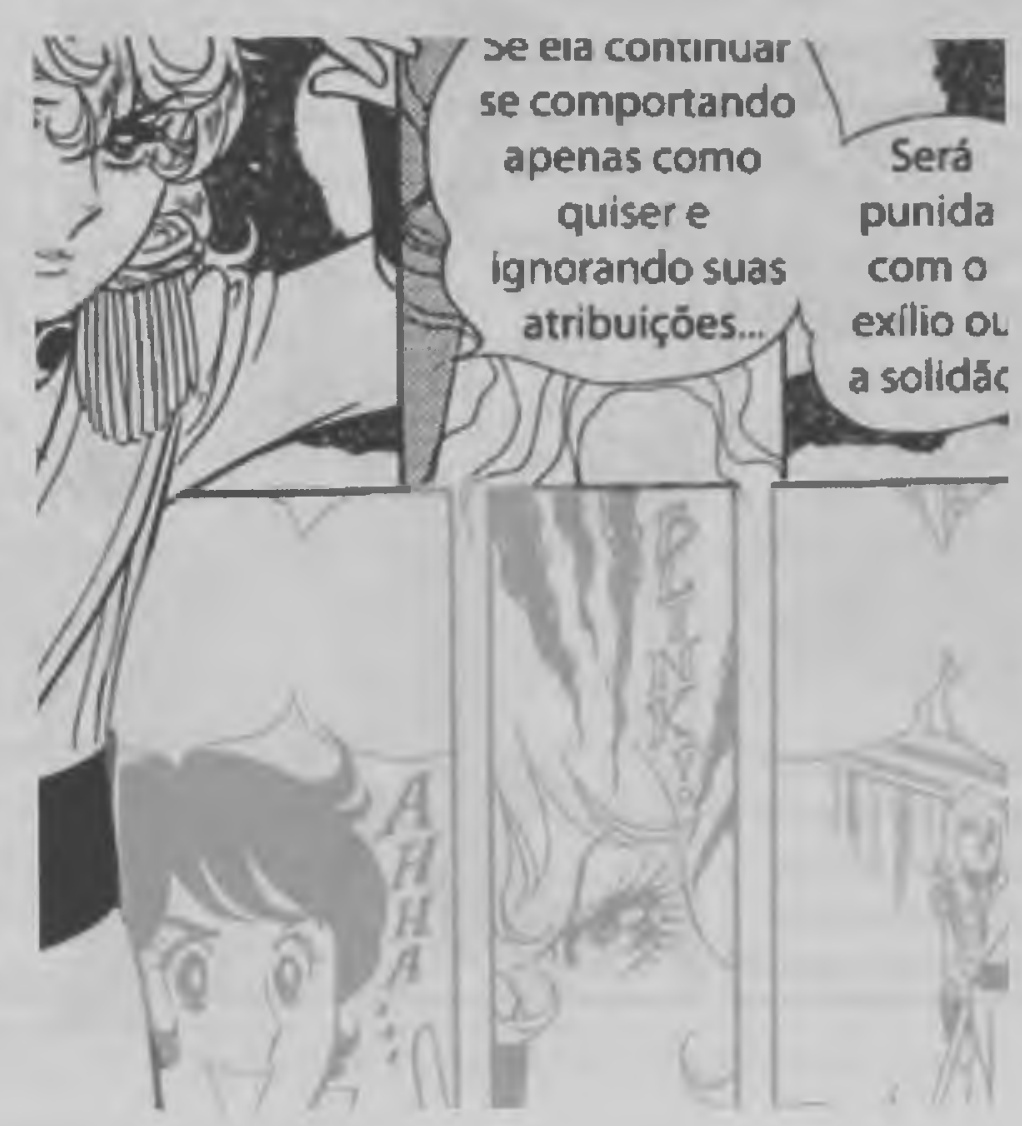

\subsubsection{Engajamento}

Intravocalização: não atribui a outra fonte a responsabilidade por suas palavras.

\subsubsection{Gradação}

Exclamações: mais uma vez as exclamações acentuam o tom do discurso de Oscar.

\subsubsection{Atitude}

Predomínio de julgamento: em "Se ela continuar se comportando (...) será punida com o exílio ou a solidão!”, há um tom crítico implícito. 


\subsection{Quarto trecho}

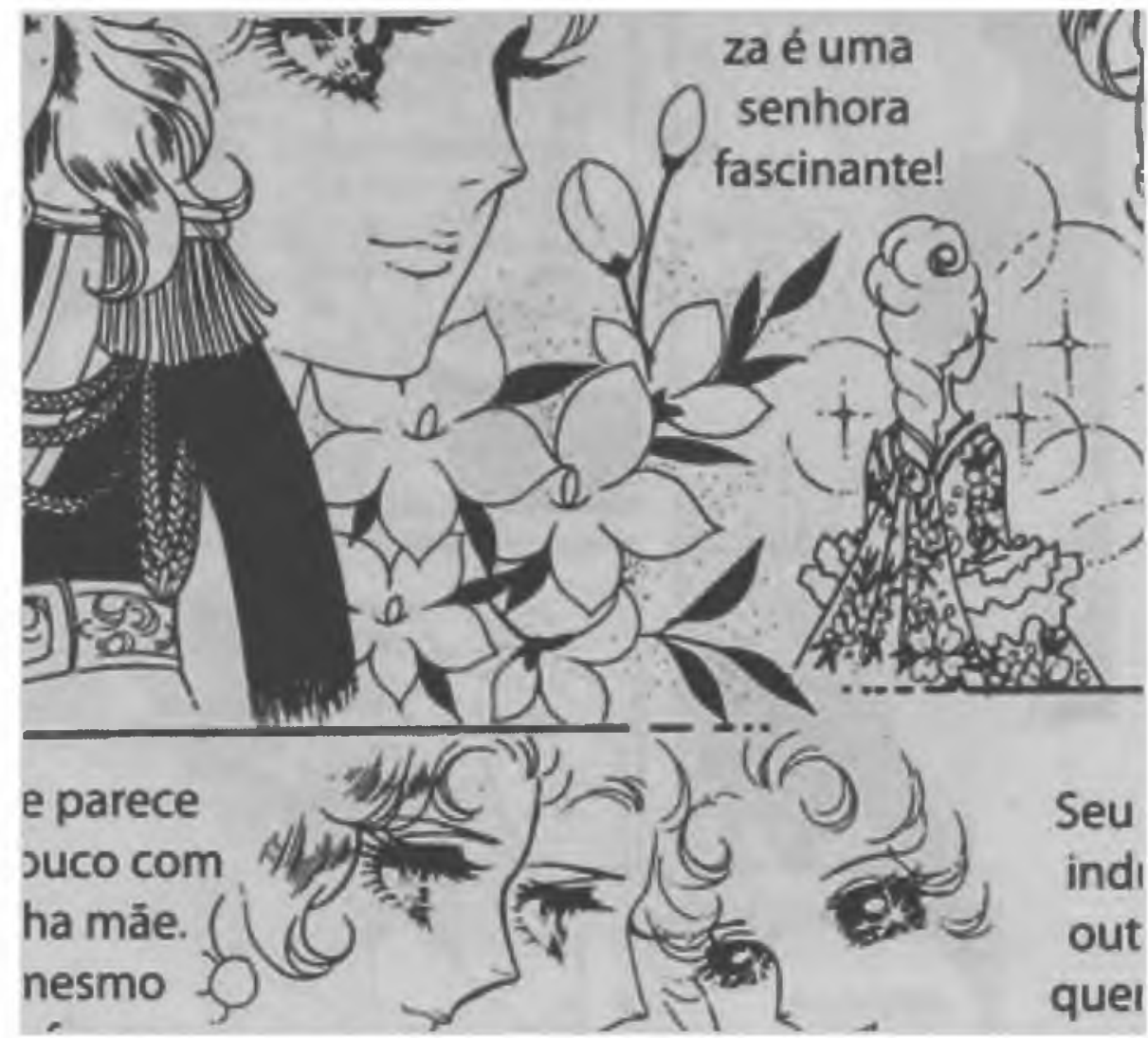

\subsubsection{Engajamento}

Intravocalização: assume a responsabilidade da fala, pois não recorre a outras fontes para endossar suas palavras.

Modalização: emprego do tempo presente do indicativo, que indica certeza. Exemplos: "é uma senhora" e "induz os outros" Há a utilização do modal "Com certeza" também.

\subsubsection{Gradação}

Léxico de tom alto: "fascinante"

\subsubsection{Atitude}

Predomínio de apreciação: "é uma senhora fascinante" 


\subsection{Quinto trecho}

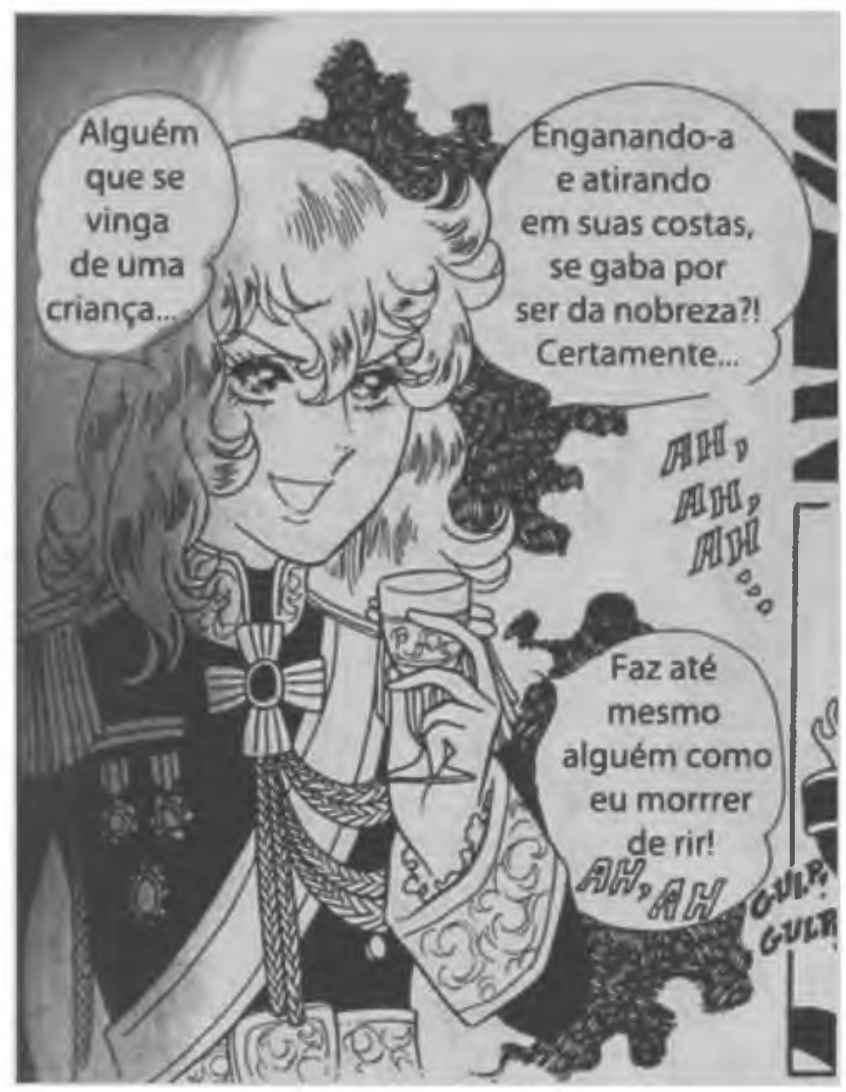

\subsubsection{Engajamento}

Intravocalização: através a frase "Faz até mesmo alguém como eu morrer de rir!", a enunciadora diz, com outras palavras, que a atitude descrita (nesse quadro) é risível para ela, assumindo a responsabilidade dessa crítica.

Modalização: "certamente", que indica algo dado como verdadeiro.

\subsubsection{Gradação}

Léxicos de tom alto: "certamente", "até mesmo" e "morrer de rir" Exclamações: acentuam o discurso.

Gargalhadas grafadas de forma diferente: destacam-se do restante do texto, elevando a tonalidade do mesmo. Desse modo, amalgamam-se os elementos textuais imagéticos e verbais.

\subsubsection{Atitude}

Predomínio de julgamento: a frase "Faz até mesmo alguém como eu morrer de rir!" retoma todo o texto do quadro e o caracteriza como uma crítica à atitude do coenunciador. 


\subsection{Sexto trecho}

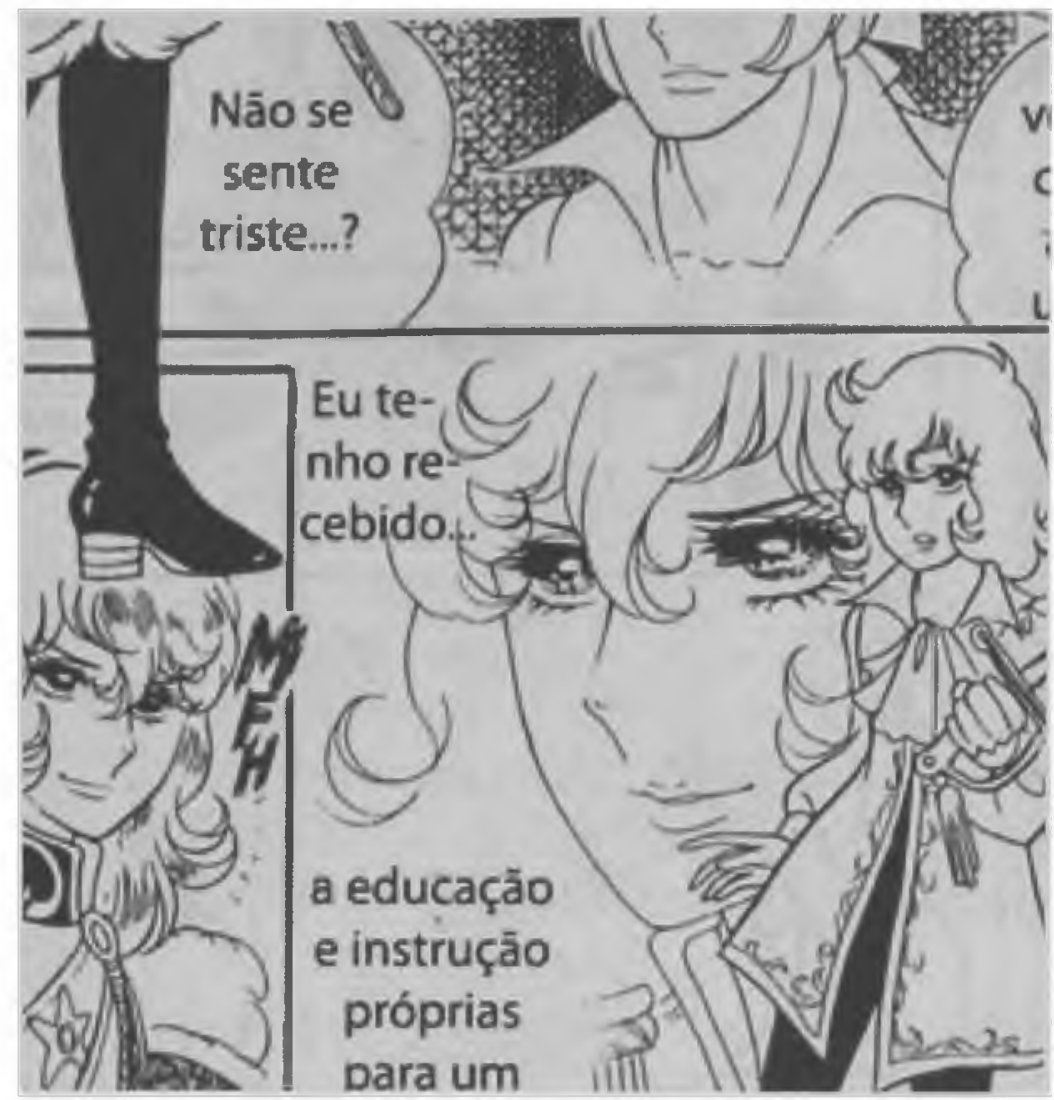

\subsubsection{Engajamento}

Intravocalização: assume total responsabilidade por suas palavras através de "Eu" e "não me parece"

Modalização: o uso de "não me parece" permite ao coenunciador um diálogo, já que não é categórico.

\subsubsection{Gradação}

Nenhum elemento presente.

\subsubsection{Atitude}

Predomínio de afeto: na polaridade positiva, embora num tom baixo devido à modalização gerada por "não me parece" 


\subsection{Sétimo trecho}

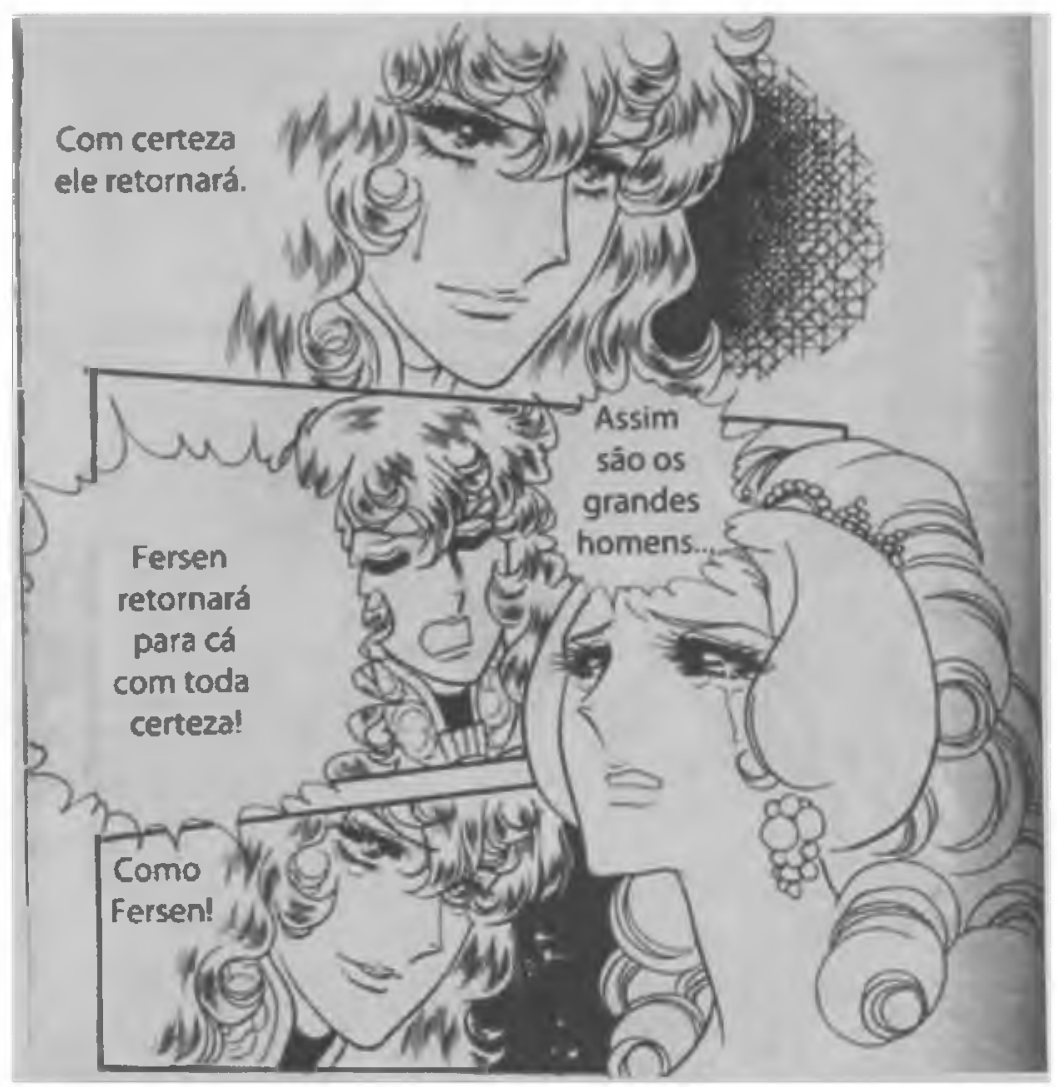

\subsubsection{Engajamento}

Intravocalização: assume a responsabilidade por suas palavras ao expressar suas opiniões.

Modalização: através do uso de "Assim", "com certeza" e "com toda certeza" e dos formas verbais do presente e do futuro do presente do indicativo, a personagem vale-se de afirmações categóricas que não deixam margem para uma contra-argumentação.

\subsubsection{Gradação}

Léxicos de tom alto: "grandes"

Exclamações: elevam o tom do discurso.

\subsubsection{Atitude}

Predomínio de julgamento: a personagem julga o comportamento dos homens com a frase "Assim são os grandes homens..." 


\section{Conclusão}

Através da análise demonstrada anteriormente é possível encontrar alguns padrões no discurso da personagem Oscar e chegar a conclusões sobre o ethos que eles propiciam à protagonista de Versailles no Bara.

\subsection{No que diz respeito ao subsistema do engajamento}

Predomínimo total de intravocalização, ou seja, a personagem utiliza suas próprias opiniões para compor seu discurso. O único endosso ao qual recorreu nos trechos apresentados foi um endosso neutro (no segundo trecho), que se referia a um consenso entre ela (a enunciadora) e os coenunciadores, ou seja, um consenso do qual ela própria também fazia parte. Porém, mesmo a utilização desse endosso não exime de Oscar a responsabilidade pelo dito, já que a enunciadora compartilha do consenso implicitamente apresentado. Desse modo, cria-se a imagem de uma mulher que é senhora de seus pensamentos, capaz de criar suas próprias concepções de mundo e de assumir a responsabilidade por seus pensamentos verbalizados diante da sociedade.

A modalização presente no discurso de Oscar é muito geralmente marcada por afirmações categóricas. A personagem utiliza comumente verbos no presente ou no futuro do presente do indicativo, o que expressa sua crença naquilo que diz, já que são tempos verbais que indicam certeza dos eventos que anunciam. O emprego de modais como "certamente" (no quinto trecho) e "com toda certeza" também dão às suas afirmações um caráter de algo tido como verdadeiro. $\mathrm{O}$ emprego de elementos discursivos que apontam para uma certeza do que é dito conferem à personagem um ethos alguém que possui segurança e confiança sobre o seu discurso, afinal, ela não é vacilante ao expressar suas opiniões, que são ditas como verdades absolutas.

\subsection{No que diz respeito ao subsistema da gradação}

No discurso de Oscar há uma grande abundância de léxicos de tom elevado, como "patético" (no primeiro trecho), "fascinante" (no quarto trecho) e "morrer de rir" (no sexto trecho). O largo emprego de exclamações para marcar o discurso de Oscar acentuam o tom alto das falas de suas falas. Esses elementos combinados sinalizam para a imagem de uma mulher com uma alta intensidade de opiniões e sentimentos e uma fala imponente, impactante.

Em uma perspectiva multimodal, considero que as gargalhadas (já comentadas anteriormente como, sem que Oscar esconda a boca com as mãos, um elemento imagético de cunho feminista quando considera-se os costumes japoneses), grafadas de modo diferente do restante do texto, atuam como um elemento de amálgama 
entre os estratos textuais verbal e imagético, propiciando uma elevação de tom nas falas presentes nos quadros em que estão situadas.

Embora em apenas um trecho entre os selecionados esse elemento tenha aparecido, seu simbolismo é marcante para a sociedade nipônica, em especial a dos anos 1970, quando o movimento feminista alcançava seu auge no Japão, por ser contrário a um costume japonês ao qual as mulheres estavam atreladas. Por isso, as gargalhadas expostas de Oscar contribuem para a formação do ethos de uma mulher que está livre das amarras impostas pela sociedade, que vive como lhe agrada e não para agradar a sociedade em que se encontra.

\subsection{No que diz respeito ao subsistema da atitude}

Há um grande predomínio de elementos de julgamento no discurso de Oscar que culminam na formação da imagem de uma mulher que não é submissa e que critica a sociedade, o que se torna mais comum ao longo da trama, dada a percepção da protagonista dos abusos cometidos pelos nobres em oposição à miséria e abandono da população menos favorecida.

Através da contraposição entre a abundância de elementos de julgamento e da presença de poucos elementos de apreciação podemos concluir que a personagem se preocupa mais com as críticas de perspectiva ética e social, já que a noção de julgamento dentro do subsistema da atitude se relaciona a um posicionamento crítico de cunho comportamental, do que com críticas de ordem estética. Esse posicionamento configura a Oscar um ethos de mulher que possui maturidade crítica e ética, opondo-se, desse modo, à noção machista do feminino enquanto um gênero que se preocupa mais com os elementos estéticos e superficiais.

Quanto à contraposição entre os muitos elementos de julgamento e os raros de afeto, conclui-se que Oscar foca suas atenções mais no mundo exterior do que em si própria, o que cria uma imagem de mulher que coloca o social em ordem de maior importância do que o pessoal, uma mulher sem apego à vaidade e ao egocentrismo.

\subsection{A divergência de elementos discursivos do sexto trecho}

No sexto trecho exposto no presente trabalho, excluindo-se a intravocalização ali empregada na fala de Oscar, todos os elementos discursivos abordados destoam dos padrões encontrados durante a análise.

Em relação ao subsistema do engajamento, a modalização cede a uma possibilidade de contra-argumentação por parte do interlocutor, já que há a utilização da expressão "não me parece" no lugar das habituais afirmações categóricas da 
personagem. Quanto à gradação, desaparecem as palavras de tom alto e as exclamações, dado lugar a um discurso mais contido. Sobre a atitude, há o predomínio de elementos de afeto e ausência de elementos de julgamento e de apreciação. O discurso ali presente, se isolado de todos os outros trechos, dá oportunidade à formação de um ethos completamente diferente do que é o padrão de Oscar.

Enquanto um trecho de exceção, poderia ser desconsiderado para fins de padrões e até mesmo não inserido neste trabalho. Porém, uma vez que se configurou de forma tão discrepante dos demais trechos apresentados (e da obra em geral), ele me levou a um questionamento do porquê dessa diferença discursiva e, por isso, acreditei ser interessante mantê-lo no trabalho.

A conclusão à qual cheguei, após reler alguns outros trechos de Versailles no Bara, é a de que sempre que Oscar dialoga sobre si mesma, o que é de certo modo raro na obra, ela deixa de ser impactante e categórica. Quando fala de si e de sua condição de mulher, apesar da imagem masculinizada, Oscar parece mais frágil e vacilante. Embora esses momentos não interfiram no padrão discursivo de Oscar - na obra a proporção entre os momentos em que Oscar dialoga sobre si e os demais momentos é ainda menor do que a proproção de 1 para 7 apresentada neste trabalho -, foi bastante interessante que a aplicação da Teoria da Valoração tenha me proporcionado essa percepção.

Buscando compreender os motivos da variação discursiva nesses momentos, primeiramente conclui que funcionaria como um elemento negativo diante do Feminismo daquelas décadas, hoje conhecido como Segunda Onda do Feminismo. Afinal, aquele movimento se preocupava em considerar a mulher como um ser igual ao homem, o que lhe justificaria desfrutar dos mesmos direitos, e Oscar ao falar sobre si mesma parece assumir toda uma feminilidade que descarta sem arrependimento nos outros momentos.

Porém, tendo em vista o Feminismo da Diferença, vertente da Terceira Onda do Feminismo, que se iniciou nos anos 1990, pode-se compreender a obra Versailles no Bara como precursora dessa tendência feminista, que encontraria seu espaço apenas duas décadas depois do lançamento da obra de Riyoko Ikeda. Desse modo, a personagem Oscar, que simbolizou toda uma geração de mulheres japonesas, é capaz de representar a imagem de uma mulher que reflete as questões feministas do mundo contemporâneo, do início do século XX.

Provavelmente por essa possibilidade de adequação ao contexto do mundo atual, reedições da obra sejam impressas de tempos em tempos no Japão, novas animações - como um filme que resume a série - sejam apresentados ao público e a adaptação teatral seja a o musical de maior sucesso do tradicional Teatro Takarazuka, do qual todos os integrantes são mulheres, atendendo aos anseios dos antigos fãs e renovando a legião de aficionados por Versailles no Bara. 


\section{Referências Bibliográficas}

ARCAND, Denys. Le Déclin de l'Empire Américain and les Invasions Barbares. Toronto: university of Toronto Press, 2008.

ECO, Umberto. Apocalípticos e Integrados. 6. ed. São Paulo: Perspectiva, 2006.

MAINGUENEAU, Dominique. Ethos, Cenografia, Incorporação. In: Imagens de Si no Discurso - a Construção do ethos. 2 ed. São Paulo: Contexto, 2011.

JAKOBSON, Roman. Linguística e Comunicação. 10. ed. São Paulo: Cultrix, 1975.

LUYTEN, Sonia M. Bibe. Mangá: o Poder dos Quadrinhos Japoneses. 2 ed. São Paulo: Hedra, 2000.

MOLINÉ, Alfons. O Grande Livro dos Mangás. São Paulo: JBC, 2004.

NAGADO, Alexandre. Almanaque da Cultura Pop Japonesa. São Paulo: Via Lettera, 2007.

NETO, Guilherme. Mangás: uma Leitura de Jovens Cariocas e Paulistas. Rio de Janeiro: 2009.

SATO, Cristiane Akune. Japop - o Poder da Cultura Pop Japonesa. São Paulo: NSP Hakkosha, 2007.

\subsection{Eletrônicas}

Appraisal Website: homepage, The. http://www.grammatics.com/appraisal/index.html (acessado em 13/7/2011).

InfoEscola. http://www.infoescola.com/historia/segunda-onda-feminista (acessado em 26/3/2012).

Mangá. Disponível em http://www.japaoonline.com.br/pt/manga2.htm (acessado em 9/7/2011).

SILVA, Valéria Fernandes da. História, shoujo mangá e feminismo: um olhar sobre a Rosa de Versalhes. In: Labrys 20, 2011. Disponível em http://www.tanianavarroswain.com.br/ labrys/labrys20/bresil/valeria.htm (acessado em 26/3/2012)

\subsection{Imagens}

IKEDA, Riyoko. Versailles no Bara. Publicado na revista Margaret. 1972. 